\title{
Chatter-call harmonics in the North Island Saddleback: do they play a role in ranging?
}

\author{
Joseph F. Azar ${ }^{\mathrm{A}, \mathrm{B}}$, Ben D. Bell ${ }^{\mathrm{A}}$ and K. C. Burns ${ }^{\mathrm{A}}$ \\ ${ }^{\mathrm{A} C e n t r e}$ for Biodiversity \& Restoration Ecology, School of Biological Sciences, Victoria University of Wellington, \\ PO Box 600, Wellington 6041, New Zealand. \\ ${ }^{\mathrm{B} C}$ Corresponding author. Email: azar.joseph@gmail.com
}

\begin{abstract}
Birds that counter-sing for communication and territorial maintenance need to localise the source of sound in order to promote an appropriate intraspecific response. Here, we investigate the role of harmonics in the chatter call of the North Island Saddleback (Philesturnus rufusater). We test whether the relative amplitude of harmonics serves as a distance cue, and whether a change of the harmonic composition of the chatter call has an effect on bird's response and its likely ability to estimate the distance of the signalling individual. North Island Saddlebacks exhibited stronger responses to playback songs with more relative energy within higher harmonics, suggesting that these are perceived as coming from a nearby individual. North Island Saddlebacks took longer to respond and counter-sang less to chatter calls with more relative energy in lower harmonics, suggesting that they were perceived as coming from a distant bird. We also found that North Island Saddlebacks responded differently to songs from which different harmonic frequencies were removed (muted). This study reveals the ability of the North Island Saddleback to differentiate between calls with different harmonic composition and proposes that harmonics are important as distance cues.
\end{abstract}

Additional keywords: bird song, Philesturnus rufusater, playback.

Received 22 June 2012, accepted 20 November 2012, published online 21 February 2013

\section{Introduction}

Acoustic signals play a significant role in animal behaviour, conveying information about signalling individuals involved in intraspecific interactions, such as repelling rivals in territorial defence or indicating the fitness of singing males to females (Krebs et al. 1978; Catchpole et al. 1984; Buchanan and Catchpole 1997; Slater 2003; Catchpole and Slater 2008). The distance of a signaller has biological significance affecting interactions within and between sexes, and transmission through the environment modifies the signal, giving receivers cues to the distance of the signaller (Catchpole and Slater 2008). For bird song, the receiver should be able to use these cues to estimate the distance of the signalling individual, a behaviour known as ranging (McGregor and Krebs 1984). Correct estimation of distance is important in determining the response of the receiver because it can lead to avoidance of unnecessary or dangerous interactions, or to the better location of a mate, or it may promote aggressive responses, to defend a territory when a rival is nearby (Richards 1981; McGregor et al. 1983; McGregor and Krebs 1984; Naguib 1995).

Few studies have focussed on the effect of frequency in ranging, although relative intensities of high frequencies have been used to estimate the distance of a signaller, for example in Carolina Wrens (Thryothorus ludovicianus) (Naguib 1995, 1997b). The combination of frequency-dependent attenuation and reverberation can also give information about the distance of the signaller (Naguib et al. 2000). Again, few studies have focussed on the role of harmonics (notes with multi-frequency bands) in ranging (e.g. Aubin and Jouventin 2002), although other aspects of the function of harmonics have been investigated. Both Zebra Finches (Taeniopygia guttata) and Budgerigars (Melopsittacus undulatus) were able to detect slight mistuning of one of the harmonics in a simulated female Zebra Finch contact call (Lohr and Dooling 1998). In Whooping Cranes (Grus americana) harmonics provide acoustic cues to individuality and body size (Fitch and Kelley 2000), and in Red-winged Blackbirds (Agelaius phoeniceus) lower frequency elements of song are essential for species recognition whereas high-frequency elements are not (Brenowitz 1982).

As the sound of a bird's vocalisation travels in the habitat, it is subject to degradation. Changes that accumulate in the songs are the result of reverberation, amplitude fluctuation and frequencydependent attenuation (Slabbekoorn et al. 2002), with higher frequencies being more susceptible to degradation (Padgham 2004). Playback experiments on birds in natural conditions demonstrate that reverberated songs are judged to be further away than undegraded songs (Fotheringham et al. 1997). Birds approach closer towards a loudspeaker playing reverberated song or even fly beyond the loudspeaker (Wiley and Godard 1996). The relative intensities of high frequencies can also be used in avian song-ranging (Naguib 1995, 1997a). Combinations of reverberation and frequency-dependent attenuation may therefore serve as 
distance cues (Naguib 1996). Amplitude varies more with weather than reverberation or frequency-dependent attenuation (Richards 1981), so changes in amplitude may provide a less reliable clue for song-ranging. Nevertheless, some species use overall amplitude as a relative cue for ranging conspecific songs (Naguib 1997a; Nelson 2000).

Different syllables in bird songs can have different spectrographic forms, whistles being a common type in which the energy is concentrated at a single frequency that may change temporally during utterance. Another type comprises multi-frequency bands of harmonics where the energy is distributed into more than one frequency, and where higher frequencies are integer multiples of the fundamental frequency. The North Island Saddleback (Philesturnus rufusater) is a member of the endemic New Zealand wattlebird family, the Callaeatidae (or Callaeidae). North Island Saddlebacks stay within and defend their territories year-round. Two subdivisions of loud North Island Saddleback song are recognised: male rhythmical songs, used exclusively by siteattached pair-bonded adult males, with each male having 1-4 patterns (Jenkins 1978), and chatter calls, which are uttered by both sexes throughout the year and are the most common song type in both paired and unpaired birds (Jenkins 1978; Parker et al. 2010). Chatter calls appear to be important in territorial maintenance and communication between territorial adults and nonterritorial juveniles (Jenkins 1978; Ludwig and Jamieson 2007). Quiet calls are used for pair-bonding and can only be heard over short distances, avoiding agonistic behaviour between residents that would result from louder long-distance signalling (Jenkins 1978). Familiarity with particular male rhythmic songs affects North Island Saddleback responses in playback experiments (Parker et al. 2010). Hence, this study focussed on the role of harmonics in the common chatter call, which is less likely to vary spatially within the study area and is given by both males and females (Jenkins 1978; Parker et al. 2010; J. F. Azar and B. Bell, pers. obs.). The chatter call consists of a set of 3-40 repeated notes, all of which consist of sets of harmonics (Fig. 1b). The fundamental frequency (F0) is $\sim 1.5 \mathrm{kHz}$, and has the lowest energy compared with other harmonics. The first harmonic (H1) is $\sim 3 \mathrm{kHz}$, whereas the second harmonic (H2) is $\sim 4 \mathrm{kHz}$ and is the dominant frequency where most of the energy in the song is present. Higher harmonics $(\mathrm{HH}),>4.5 \mathrm{kHz}$, have lower energy and are more susceptible to attenuation.

Pitch is the perception of frequency and, in tonal avian song, pitch is often a direct function of the fundamental frequency (Lord et al. 2009). It can also be determined by harmonics in the upper frequency range that have greater energy than the fundamental, hence pitch may be relative with respect to F0 (Lord et al. 2009). In humans, F0 affects the judgement of both voice quality and recognition (Handel 1995). In other primates, assessing the identity of the caller relies on harmonic structure and harmonic relationships, rather than on the presence of a single harmonic frequency, for example in Japanese Macaques (Macaca fuscata) (May et al. 1989) and Cottontop Tamarins (Saguinus oedipus) (Weiss and Hauser 2002).

Here we explore whether the North Island Saddleback uses harmonics as a cue for distance by observing the responses of birds to artificially modified chatter call segments using playback experiments. Given that higher harmonics are more susceptible to attenuation than those at lower frequency (Padgham 2004), songs with relatively more energy in higher harmonics are predicted to produce a greater response than songs with relatively more energy in the lower harmonics, when broadcast with similar amplitude and from the same distance (Brumm and Slater 2006). Further, we investigate whether the North Island Saddleback is sensitive to changes in the harmonic composition of its chatter call, and how it responds to songs from which some harmonics are removed. Because muting any of the harmonics affects the overall pitch and the energy in the song (Darwin et al. 1994), this result in different transmission properties of the song. We predict that modified songs with muted harmonics will give a false cue of the broadcast location and that this will affect the distance to which the birds approach the speaker. Because harmonics with higher energy transmit further, we predict that muting harmonics with high energy (H1, H2) will have more effect on song-ranging, and that birds will be less able to locate the speaker. Because higher harmonic $(\mathrm{HH})$ bands attenuate more when transmitted in the forest, and the North Island Saddlebacks will be accustomed to this, we predict that muting higher harmonics will not affect their ability to locate the speaker.

\section{Methods}

Study site

To avoid disturbance during the height of the breeding season (October-February), the experiments were conducted from March to April 2011 in Zealandia, a 250-ha native-forest sanctuary surrounded by a mammal-proof fence within the city limits of Wellington, New Zealand $\left(41^{\circ} 17.8^{\prime} \mathrm{S}, 174^{\circ} 45.3^{\prime} \mathrm{E}\right)$.

\section{Playback signal design}

The modified natural chatter call extracts used in the playback experiments were recorded in 2009 from the same Saddleback population using a Marantz PMD670 portable solid-state recorder (Marantz Europe, Eindhoven, the Netherlands) with a sampling frequency of $44.1 \mathrm{kHz}$ and 16-bit sample size. One good-quality recording of a chatter call was selected to produce the modified songs using Adobe Audition 3 (Adobe San Jose, CA, USA) and Raven Pro 1.4 software (Cornell Laboratory of Ornithology, Ithaca, NY, USA). To standardise the stimulus and attenuation accumulated in it, the stimulus was therefore developed from a single call. Pseudoreplication might arise if such a single exemplar from a class of stimuli was used to test a general hypothesis about the class itself (Kroodsma et al. 2001). However, this study tests the specific role of harmonics as a distance cue in chatter calls, but not the more general role of chatter calls in communication.

We were unable to confirm the sex of birds attracted by the playback sounds, except for those that were colour-banded ( 2 males and 1 female). We conducted two experiments. For the first experiment (Experiment 1), to test the response to modifications in harmonics intensity, two types of modification were made (Fig. 1): (1) amplification of lower harmonics (ALH) with the attenuation of the higher harmonics, so that the overall energy in the song remained unchanged (Fig. 1a) and (2) amplification of higher harmonics $(\mathrm{AHH})$ with reduction of the energy in the lower frequency harmonics. We used the unmanipulated song (Fig. 1b) as the control. All three-treatments had the same amount of energy 
(a)

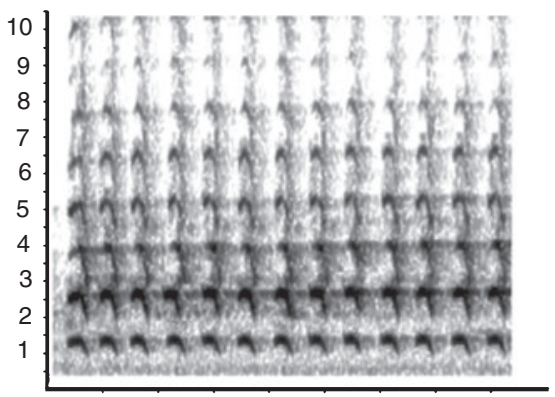

(b)

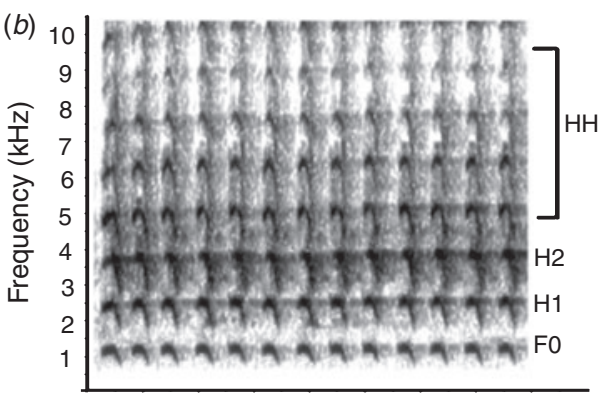

(c)

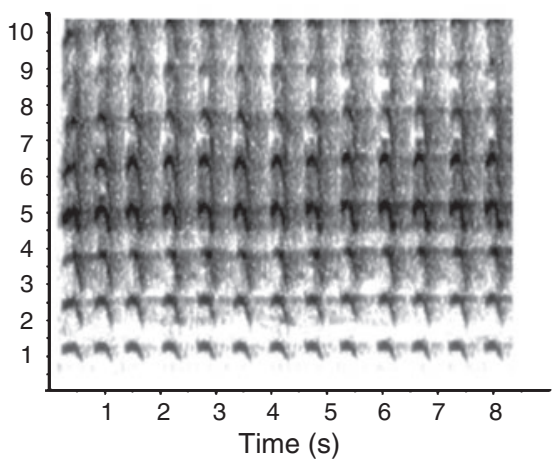

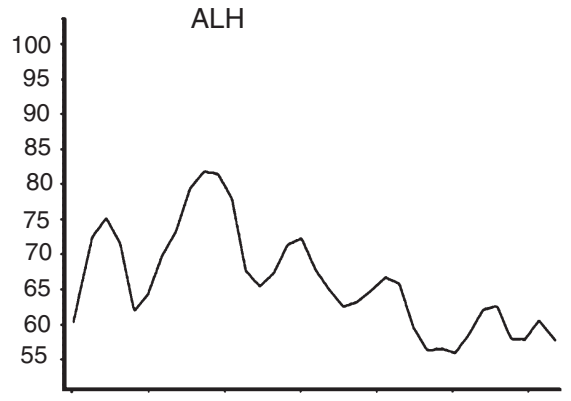
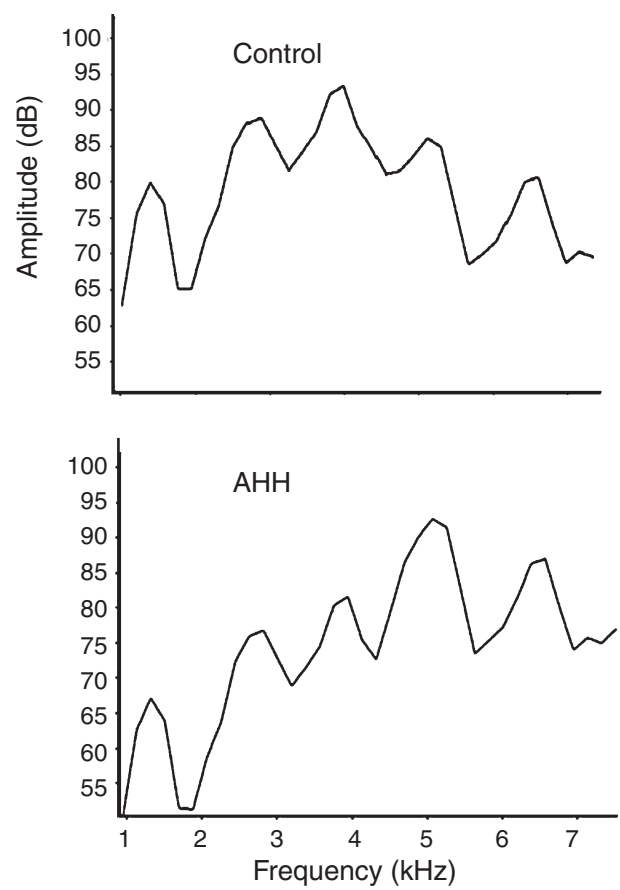

Fig. 1. Spectrograms (up to $10 \mathrm{kHz}$, left) and power spectra (up to $7 \mathrm{kHz}$, right) of an 8-s sample of North Island Saddleback chatter call, the first $5 \mathrm{~s}$ of which were used in playback experiments: $(a)$ amplified lower harmonics $(\mathrm{ALH}) ;(b)$ control (unmodified song) showing the fundamental frequency ( $\mathrm{F} 0$ ) and the harmonics $(\mathrm{H} 1, \mathrm{H} 2, \mathrm{HH})$ and (c) amplified higher harmonics (AHH). The darkness of the bands in the spectrograms represents the relative amplitude in the song.

$(125 \mathrm{~dB})$ but with differing amplitude distributions across the frequency spectrum. All songs used in the playback experiments were $5 \mathrm{~s}$ long. For the second experiment (Experiment 2), to test the response to muted harmonics, the song was modified by muting each of the harmonic bands of the $\mathrm{F} 0, \mathrm{H} 1, \mathrm{H} 2$ and $\mathrm{HH}$ (Fig. 2); again, the songs were of 5-s duration. The same unmodified song was used as a control in both experiments.

\section{Field protocol for playback}

We conducted playback experiments on 13 birds at 13 sites, each at least $400 \mathrm{~m}$ apart to provide a substantial degree of vocal isolation between experiments. We tested three birds each day. The two experiments were run separately: Experiment 1 was run first, Experiment 2 began 4 days after all birds had been tested in Experiment 1.

At each site, two speakers were set up. One speaker (A) was a Sony portable RDPM5iP speaker (Sony Corp., Tokyo, Japan), placed in the forest $3 \mathrm{~m}$ above the ground in vegetation attached to tree branch, and used to first attract the target bird by playing unmodified calls (from a different individual than the unmodified calls used in the experiments), ensuring that the bird was consistently positioned at a similar distance from the second speaker (B). The second speaker was a Mipro MA-101 (MIPRO Electronics Co., Ltd., Chiayi, Taiwan), attached to tree branch $2 \mathrm{~m}$ above the ground and camouflaged by leaves to prevent the bird from acquiring any visual cues to its location; it was used for playback of the experimental stimuli. Calls were played back using an iPod nano (Apple Inc., Redlands, CA) playing MP3 files (MP3 is a compressed file type that might conceivably affect the response of the birds to a minor degree). The two speakers were wired to the same iPod, $15 \mathrm{~m}$ away from each; the researcher was concealed in dense vegetation. Speakers were set to a constant output volume. When the bird was within $2 \mathrm{~m}$ of speaker A, we allowed 2-4 min for the bird to settle, and then one stimulus call (one $5 \mathrm{~s}$-long modified or control Chatter Call) was played from 


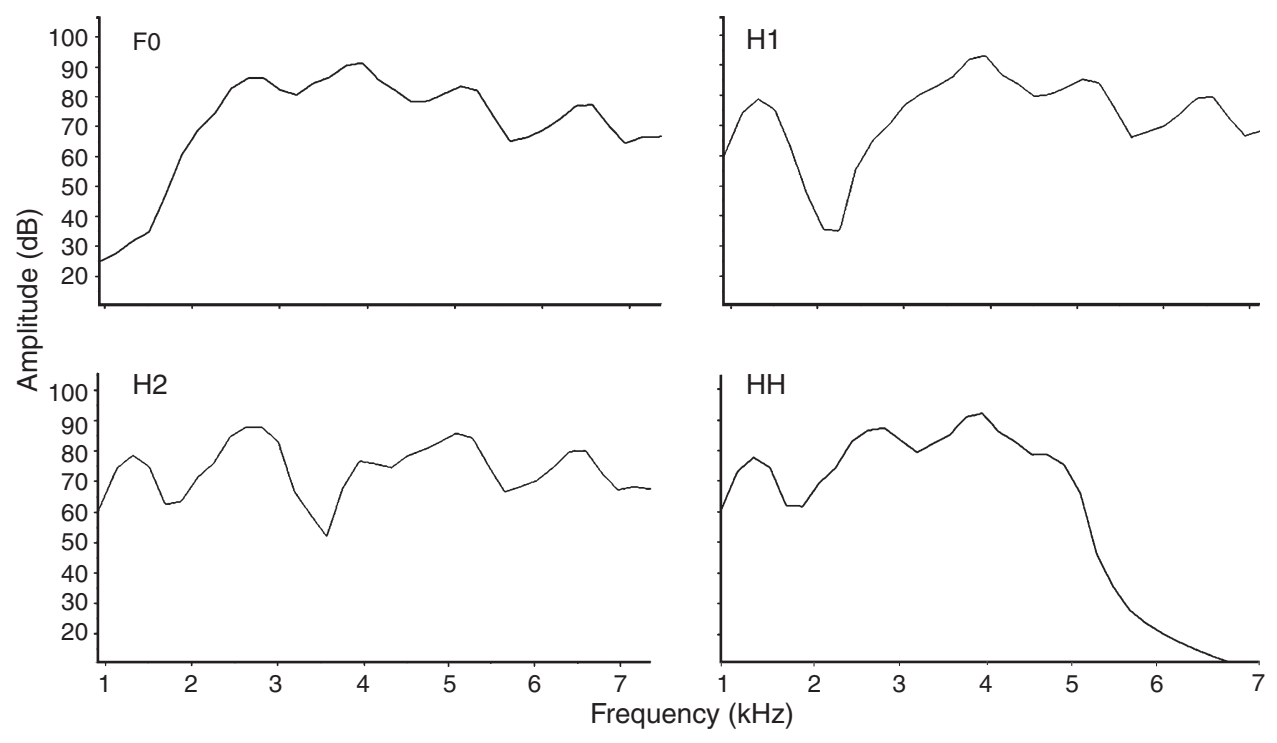

Fig. 2. Power spectra of four chatter call samples modified for use in Experiment 2, showing muted fundamental frequency (F0), muted first harmonic (H1), muted second harmonic (H2) and muted higher harmonics $(\mathrm{HH})$.

speaker B and the response of the birds recorded (within $2 \mathrm{~min}$ ). After playback of each stimulus, we waited 10-15 min (from the conclusion of the bird's response) then again broadcast the unmodified song from speaker A to bring the same bird (as monitored by researcher) back to the starting position and the next stimulus was played (see below for details of call sequences and responses measured). These procedures were repeated until all the modified calls in an experiment had been played to an individual bird. The order in which each stimulus was played to different birds was randomised to eliminate any chance of the targets acquiring more location cues about the source of the sound. If on any occasion two birds were simultaneously attracted to speaker (A), then the experiment was terminated for that site.

In Experiment 1 , each subject $(n=13)$ received six playbacks two repeats of each the three chatter-call types $(\mathrm{ALH}, \mathrm{AHH}$, Control) - presented in random order. Two responses were measured: (1) time (s) to the first vocal response (counter-singing the stimulus), measured from the moment of the start of the stimulus and (2) duration of counter-song (s) in response to the stimulus. In Experiment 2, each subject $(n=13)$ received five playbacks of songs with muted harmonics (F0, H1, H2, HH, Control) presented in random order. Five responses were measured: (1) vocal response to the stimulus (Yes, No); (2) time of the first vocal response (s); (3) time until first flight or movement towards the speaker (s); (4) distance (m) of the bird after $30 \mathrm{~s}$ and (5) the closest distance $(\mathrm{m})$ to speaker B within 2 min, measured from speaker A. We used a marked 20-m rope to measure the approach distance of the bird after the bird had stopped moving toward speaker B.

The responses of birds to the modified chatter calls was examined using a general linear model (GLM) and a Tukey's honestly significant difference (HSD) test to identify significant differences between responses to each stimulus. SPSS 18 (SPSS Inc., Chicago, IL, USA) was used to perform all statistical tests. In both experiments, the measured responses were the dependent variables, the stimulus and the order they were played were the fixed factors. Bird identity was entered as a random factor to take into account repeated-measurements on individuals and intraindividual variance (Littel et al. 1991).

\section{Results}

Experiment 1: the response to modifications in harmonics intensity

Most birds (12 of 13) responded to the three treatments, only one showing no interest in the playback. The response of all 12 birds was swift and aggressive, all counter-singing to all three stimuli soon after the stimulus had ended and then approaching the speaker. The order in which the stimuli was played did not have an effect on the time to first vocal response $\left(F_{2,11}=1.29, P=0.28\right)$ or on duration of counter-song $\left(F_{2,10}=0.83, P=0.44\right)$. The duration of counter-song in response to the control playback was approximately equal to the duration of the stimulus (5 s) (Fig. 3).

There were significant differences in the response time $\left(F_{2,11}=19.9, \quad P=0.03\right)$ and duration of counter-song $\left(F_{2,10}=32.7, P<0.01\right)$ between stimuli (Fig. 3$)$. Birds responded significantly faster to the AHH playback compared with the ALH playback (Tukey's HSD, $P<0.01$ ), but the response was not significantly faster than that of the control (Tukey's HSD, $P=0.72$ ). Two birds counter-sang to the ALH playback 17-21 s after the end of the stimulus. Removing these two extreme responses from the analysis did not affect the significance of the result $\left(F_{2,9}=11.85, P<0.01\right)$ and birds responded faster to $\mathrm{AHH}$ than ALH(Tukey's HSD, $P<0.01$ ). The duration of counter-song in response to the AHH playback was significantly longer than to the ALH playback (Tukey's HSD, $P<0.01$ ) and to the control playback (Tukey's HSD, $P<0.01$ ) (Fig. 3).

\section{Experiment 2: the response to muted harmonics}

Most birds (12 of 13) counter-sang to the unmodified control chatter call, whereas only four responded to playback of songs 


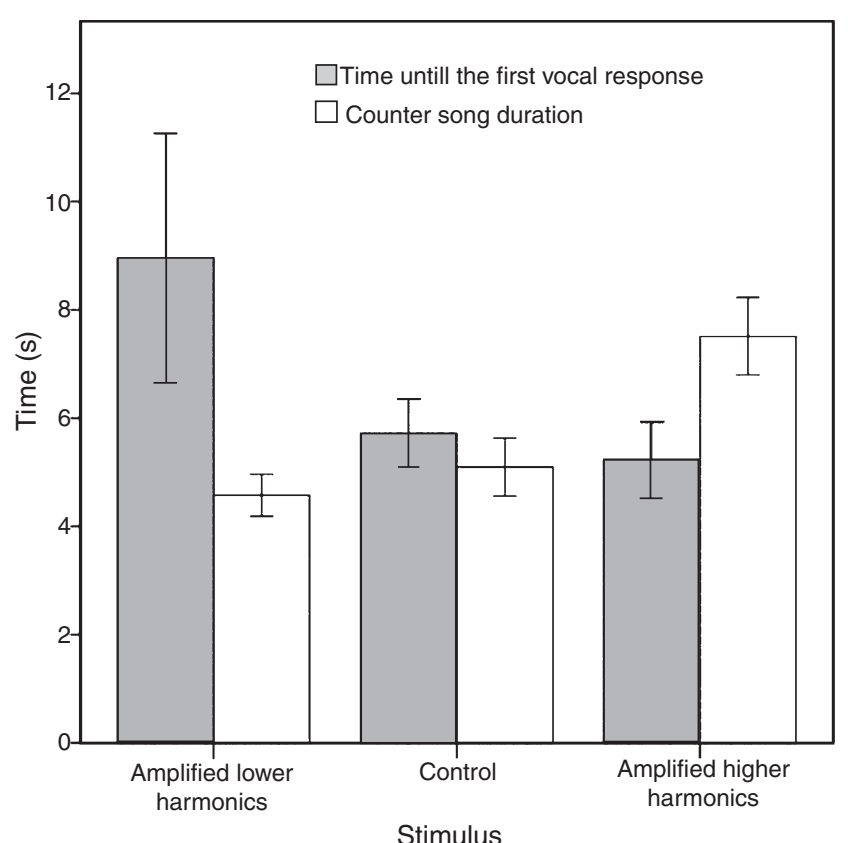

Fig. 3. Bar chart of the time to the first vocal response, and duration of counter-song for the 12 responding North Island Saddlebacks in Experiment 1. Error bars indicate standard errors.

with muted $\mathrm{F} 0$, six to muted $\mathrm{H} 1$, one to muted $\mathrm{H} 2$ and three to muted HH. Change in harmonic composition of the song by muting selected harmonics therefore caused a significant change in the vocal response of North Island Saddlebacks, and whether or not they would counter-sing $\left(F_{4,11}=6.4, P<0.01\right)$. All playback stimuli captured the attention of the targeted birds and stimulated them to approach the speaker. The control stimulated the birds to counter-sing after the stimulus ended and then to fly towards speaker B within 5-10 s (Fig. 4). The mean time of the first flight differed significantly with a change in stimulus $\left(F_{4,11}=9.2, P<0.01\right)$. Multiple comparisons revealed that F0, $\mathrm{H} 1$ and $\mathrm{HH}$ playbacks stimulated the bird to search for the source of the sound faster than $\mathrm{H} 2$ and the control playbacks (Tukey's HSD, $P<0.05)$. Nevertheless, there was no significant difference between the response to $\mathrm{F} 0, \mathrm{H} 1$ or $\mathrm{H} 2$ and control stimuli (Tukey's HSD, $P>0.05$ ).

All the birds moved towards speaker B after stimuli were played (Fig. 5). The mean distance at $30 \mathrm{~s}$ differed with change of stimulus $\left(F_{4,11}=54.8, P<0.01\right)$. Distances after 2 min were also significantly different $\left(F_{4,11}=100.36, P<0.01\right)$. Subjects moved significantly faster towards the speaker (expressed by the distance at $30 \mathrm{~s}$ ) when presented with the control and $\mathrm{H} 2$ songs compared with the other playback treatments (Tukey's HSD, $P<0.05$ ). The response to $\mathrm{HH}$ was significantly slower than the response to $\mathrm{F} 0$, $\mathrm{H} 2$ and control playbacks (Tukey's HSD, $P<0.05$ ). There was no significant difference between the response to F0 and H1 playbacks (Tukey's HSD, $P=0.15$ ).

In total 12 of the 13 North Island Saddlebacks were able to locate the speaker (indicated by the final distance from the speaker within $2 \mathrm{~min}$ ) when presented with the control chatter call, approaching within $2 \mathrm{~m}$ of speaker B or flying over it. Subjects flew over the speaker when presented with the $\mathrm{H} 2$ song and

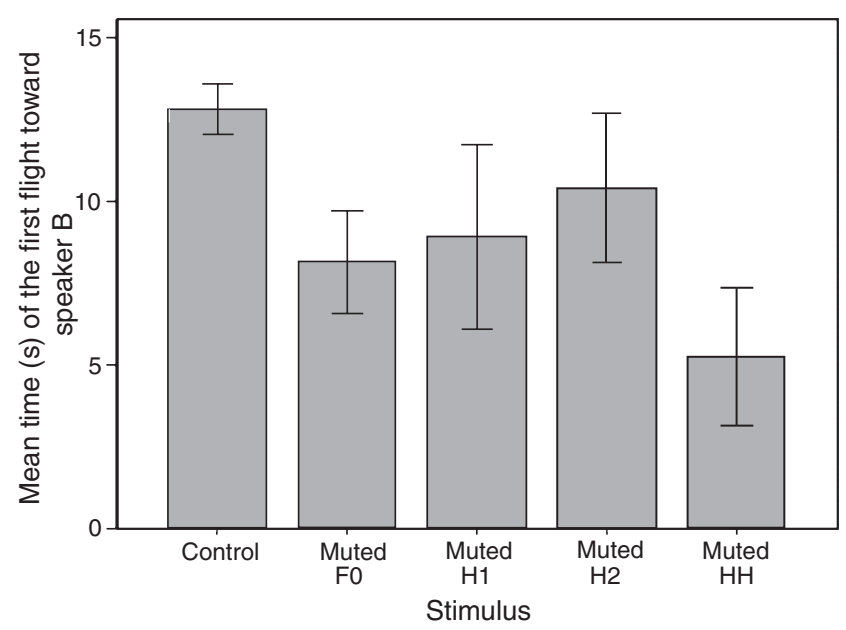

Fig. 4. Box plot of the mean times $(n=12)$ to the first flight towards the speaker in response to playback treatments in Experiment 2 (control, and muted F0, H1, H2 and $\mathrm{HH}$ ). Error bars indicate standard errors.

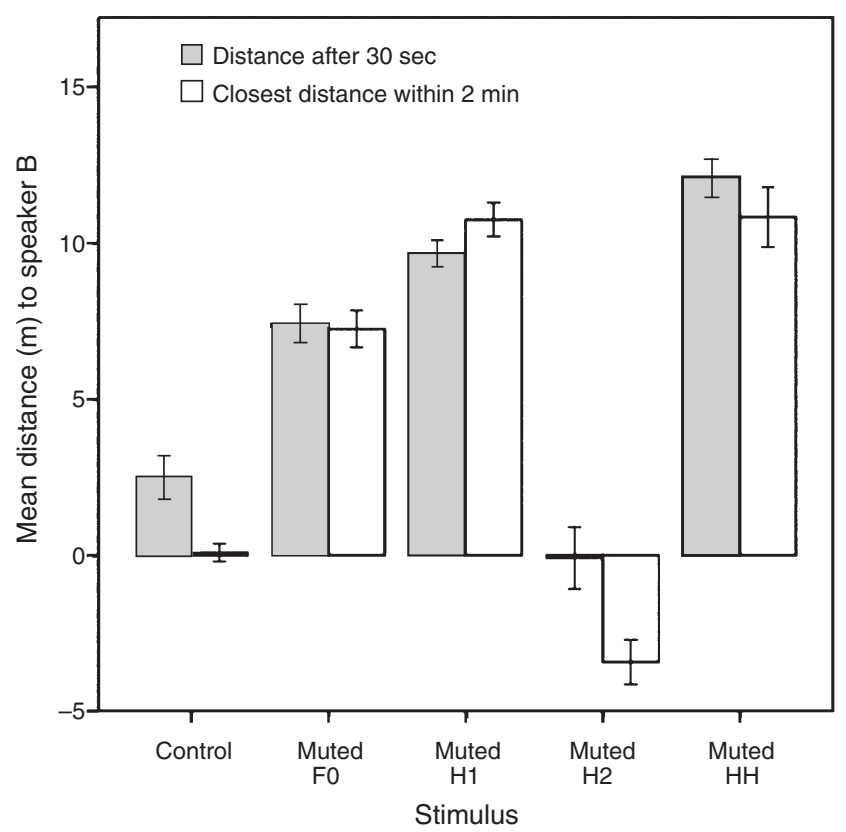

Fig. 5. Box plot of the mean distance of North Island Saddlebacks $(n=12)$ $30 \mathrm{~s}$ after stimulus playback and mean closest distance to speaker B within 2 min of start of playback in relation to different playback treatments in Experiment 2 (control, and muted F0, H1, H2 and $\mathrm{HH}$ ). A negative distance indicates that bird flew over speaker B (in response to control song type and muted $\mathrm{H} 2$ only).

were a mean final distance after $2 \mathrm{~min}$ of $3.4 \mathrm{~m}$ from speaker B, significantly different from the response to the control (Tukey's HSD, $P<0.05$ ). How close birds approached the speaker in response to the $\mathrm{F} 0$ song was significantly less than the distance in response to the control and $\mathrm{H} 2$ playback, but greater than the distance in response to $\mathrm{H} 1$ and HH playback (Tukey's HSD, $P<0.05$ ). Subjects stayed a similar distance (Tukey's HSD, 
$P=1.00)$ in response to the $\mathrm{H} 1$ and $\mathrm{HH}$ playbacks, significantly different from the response to $\mathrm{F} 0, \mathrm{H} 2$ and control playbacks (Tukey's HSD, $P<0.05$ ).

\section{Discussion}

We found from Experiment 1 that North Island Saddlebacks had a stronger response towards chatter calls with more relative energy in the higher harmonics than towards chatter calls with more energy in the lower harmonics. The former can be interpreted as coming from a closer mate or rival, thus leading to an increased response, as demonstrated by the shorter time to counter-sing and the longer duration of counter-singing. The North Island Saddleback presumably modified its response according to its perception of the proximity of the sound source in a cost-effective way, by reducing the duration of counter-song in response to songs that appeared to be further away or by increasing its response to songs that appeared closer.

Songs used in the playback experiments were broadcast from the same distance and with similar overall amplitude, allowing similar amounts of reverberation and amplitude fluctuation to occur, so it seems less likely that the North Island Saddleback would obtain distance cues from these factors, as found in previous studies showing birds useing frequency as a cue for distance (Naguib 1995, 1997a; Naguib and Wiley 2001). Our results suggest that the North Island Saddleback is less sensitive to a change in relative harmonic amplitudes than to a change in harmonic composition. All individuals responded vocally to playback in Experiment 1, but their response varied significantly in response to muting any of the harmonics.

North Island Saddlebacks were able to differentiate clearly between different harmonics in chatter calls. There was variation between vocal responses of individuals, however, although all muted playbacks prompted the bird to look for the speaker. Budgerigars and Zebra Finches can both detect mistuned harmonics and with greater acuity than humans, indicating that harmonics can have an important role in communication and might potentially encode significant information about the signaller (Lohr and Dooling 1998). Further, harmonics may be used as vocal signatures for individual discrimination, whereas they can also reveal such information as the age (Fitch and Kelley 2000), sex or reproductive maturity (Marion 1977; Fitch 1999) and size of the caller, as proposed by the size exaggeration hypothesis (Fitch 1999).

We have not addressed the specific role of each harmonic in the perception of the song, but have rather focussed on the role of harmonics in ranging. An unexpected result was that chatter calls with muted H2 (maximum frequency) stimulated North Island Saddlebacks to a faster flight towards the speaker, although the birds failed to respond vocally and were unable to locate the speaker. This suggests that $\mathrm{H} 2$ had little use in ranging but might contain information about bird identity that stimulated the bird to look for the source of the sound. The birds were unable to locate the speaker with muted $\mathrm{F} 0, \mathrm{H} 1$ and $\mathrm{H} 2$ playbacks. We found no significant difference in the final distance to speaker B across these muted song playbacks so the complete set of harmonics might be necessary to localise the source of the sound. Considering the high energy in the second harmonic (H2) compared with any of the F0, H1 and HH stimuli, the North Island Saddleback appears to use amplitude as a relative cue of distance but not as an absolute cue for ranging, because the final distance towards the speaker was significantly lower for $\mathrm{H} 2$ than for any of F0, $\mathrm{H}$ and $\mathrm{HH}$ song playback types.

Factors that may influence frequency patterns in avian song include bill-gape and vocal track filtering. Some birds are able to produce higher frequencies when increasing the bill-gape during song production; this was shown in studies on White-throated Sparrows (Zonotrichia albicollis), Swamp Sparrows (Melospiza georgiana) (Westneat et al. 1993) and Song Sparrows (Melospiza melodia) (Podos et al. 1995). In Zebra Finches, the fundamental and maximum frequencies were highly correlated with bill-gape, however this had little effect on harmonic composition (Goller et al. 2004). Tracheal length can also affect song frequency, Fitch (1999) proposing that tracheal elongation lowers the frequencies of harmonics but has little effect on the fundamental frequency. Some passerine species, such as the Trumpet Manucode (Phonygammus keraudrenii), exhibit elongated tracheae that are assumed to lower the pitch of the vocalisations (Clench 1978). Modification of harmonic structure might have biological implication, for example adaptation to the changing in transmission properties of the habitat with different season (Naguib 1996), or exaggerating a bird's apparent size (Fitch 1999; Fitch and Hauser 2003). The effect of bill-gape and tracheal elongation on harmonics in North Island Saddleback song are not studied and worth further investigation.

Our experiments on the North Island Saddleback support previous studies about the role of relative frequency attenuation in ranging (Naguib 1995), highlighting the importance of harmonics as distance cues in the North Island Saddleback chatter call, the birds differentiating between songs with different harmonic composition and responding to them accordingly. More detailed acoustic experiments and analysis, facilitated by developing acoustical software packages, are needed to explore further the role of each harmonic in North Island Saddleback communication, such as their importance as cues to individuality, fitness indicators and in individual location within the territory. Further investigations could also extend to the more complex and varied male rhythmical songs, where distance cues are again likely to be of importance (Jenkins 1978; Parker et al. 2010).

\section{Acknowledgements}

We thank the Karori Sanctuary Trust, Dr Dalice Sim for statistical advice, E. Puteri and H. Carson for assistance in the field, H. Constable for commenting on an earlier draft of the manuscript, and a Centre for Biodiversity and Restoration Ecology Scholarship and an Ian Swingland Research Scholarship at Victoria University for financial support.

\section{References}

Aubin, T., and Jouventin, P. (2002). Localisation of an acoustic signal in a noisy environment: the display call of the King Penguin Aptenodytes patagonicus. Journal of Experimental Biology 205, 3793-3798.

Brenowitz, E. A. (1982). Long-range communication of species identity by song in the Red-winged Blackbird. Behavioral Ecology and Sociobiology 10, 29-38. doi:10.1007/BF00296393

Brumm, H., and Slater, P. J. B. (2006). Animals can vary signal amplitude with receiver distance: evidence from Zebra Finch song. Animal Behaviour 72, 699-705. doi:10.1016/j.anbehav.2006.01.020 
Buchanan, K. L., and Catchpole, C. K. (1997). Female choice in the Sedge Warbler Acrocephalus schoenobaenus multiple cues from song and territory quality. Proceedings of the Royal Society of London. Series B. Biological Sciences 264, 521-526. doi:10.1098/rspb.1997.0074

Catchpole, C. K., and Slater, P. J. B. (2008). 'Bird Song. Biological Themes and Variations.' (Cambridge University Press: Cambridge, UK.)

Catchpole, C. K., Dittami, J., and Leisler, B. (1984). Differential responses to male song repertoires in female songbirds implanted with oestradiol. Nature 312, 563-564. doi:10.1038/312563a0

Clench, M. H. (1978). Tracheal elongation in birds-of-paradise. Condor 80, 423-430. doi:10.2307/1367193

Darwin, C. J., Ciocca, V., and Sandell, G. J. (1994). Effects of frequency and amplitude modulation on the pitch of a complex tone with a mistuned harmonic. Journal of the Acoustical Society of America 95, 2631-2636. doi:10.1121/1.409832

Fitch, W. T. (1999). Acoustic exaggeration of size in birds via tracheal elongation: comparative and theoretical analyses. Journal of Zoology 248, 31-48. doi:10.1111/j.1469-7998.1999.tb01020.x

Fitch, W. T., and Hauser, M. D. (2003). Unpacking 'honesty': vertebrate vocal production and the evolution of acoustic signals. In 'Acoustic Communication'. (Eds A. M. Simmons, A. N. Popper and R. R. Fay.) pp. 65-137. (Springer: New York.)

Fitch, W. T., and Kelley, J. P. (2000). Perception of vocal tract resonances by Whooping Cranes Grus americana. Ethology 106, 559-574. doi:10.1046/ j.1439-0310.2000.00572.x

Fotheringham, J. R., Martin, P. R., and Ratcliffe, L. (1997). Song transmission and auditory perception of distance in Wood Warblers (Parulinae). Animal Behaviour 53, 1271-1285. doi:10.1006/anbe.1996.0361

Goller, F., Mallinckrodt, M. J., and Torti, S. D. (2004). Beak gape dynamics during song in the Zebra Finch. Journal of Neurobiology 59, 289-303. doi: $10.1002 /$ neu. 10327

Handel, S. (1995). Timbre perception and auditory object identification. In 'Hearing'. (Editor: B. C. J. Moore.) pp. 425-461. (Academic Press: San Diego, CA.)

Jenkins, P. F. (1978). Cultural transmission of song patterns and dialect development in a free-living bird population. Animal Behaviour 26, 50-78. doi:10.1016/0003-3472(78)90007-6

Krebs, J., Ashcroft, R., and Webber, M. (1978). Song repertoires and territory defence in the Great Tit. Nature 271, 539-542. doi:10.1038/271539a0

Kroodsma, D., Byers, B., Goodale, E., Johnson, S., and Liu, W. (2001). Pseudoreplication in playback experiments, revisited a decade later. Animal Behaviour 61, 1029-1033. doi:10.1006/anbe.2000.1676

Littel, R. C., Freund, R. J., and Spector, P. C. (1991). 'SAS System for Linear Models.' (SAS Institute Inc.: Cary, NC.)

Lohr, B., and Dooling, R. J. (1998). Detection of changes in timbre and harmonicity in complex sounds by Zebra Finches (Taeniopygia guttata) and Budgerigars (Melopsittacus undulatus). Journal of Comparative Psychology 112, 36-47. doi:10.1037/0735-7036.112.1.36

Lord, K., Feinstein, M., and Coppinger, R. (2009). Barking and mobbing. Behavioural Processes 81, 358-368. doi:10.1016/j.beproc.2009.04.008

Ludwig, K., and Jamieson, I. G. (2007). Phrase types, repertoire size and repertoire overlap in the South Island Saddleback (Philesturnus carunculatus carunculatus). Notornis 54, 201-213.

Marion, W. R. (1977). Growth and development of the Plain Chachalaca in South Texas. Wilson Bulletin 89, 47-56.

May, B., Moody, D. B., and Stebbins, W. C. (1989). Categorical perception of conspecific communication sounds by Japanese Macaques, Macaca fuscata. Journal of the Acoustical Society of America 85, 837-847. doi:10.1121/1.397555

McGregor, P. K., and Krebs, J. R. (1984). Sound degradation as a distance cue in Great Tit (Parus major) song. Behavioral Ecology and Sociobiology 16, 49-56. doi:10.1007/BF00293103

McGregor, P. K., Krebs, J. R., and Ratcliffe, L. M. (1983). The reaction of Great Tits (Parus major) to playback of degraded and undergraded songs: the effect of familiarity with the stimulus song type. Auk 100, 898-906.

Naguib, M. (1995). Auditory distance assessment of singing conspecifies in Carolina Wrens: the role of reverberation and frequency-dependent attenuation. Animal Behaviour 50, 1297-1307. doi:10.1016/0003-3472 (95) $80045-X$

Naguib, M. (1996). Auditory distance estimation in song birds: implications, methodologies and perspectives. Behavioural Processes 38, 163-168. doi:10.1016/0376-6357(95)00077-1

Naguib, M. (1997a). Ranging of songs in Carolina Wrens: effects of familiarity with the song type on use of different cues. Behavioral Ecology and Sociobiology 40, 385-393. doi:10.1007/s002650050354

Naguib, M. (1997b). Use of song amplitude for ranging in Carolina Wrens, Thryothorus ludovicianus. Ethology 103, 723-731. doi:10.1111/j.14390310.1997.tb00181.x

Naguib, M., and Wiley, R. H. (2001). Estimating the distance to a source of sound: mechanisms and adaptations for long-range communication. Animal Behaviour 62, 825-837. doi:10.1006/anbe.2001.1860

Naguib, M., Klump, G. M., Hillmann, E., Griessmann, B., and Teige, T. (2000). Assessment of auditory distance in a territorial songbird: accurate feat or rule of thumb? Animal Behaviour 59, 715-721. doi:10.1006/ anbe.1999.1354

Nelson, B. S. (2000). Avian dependence on sound pressure level as an auditory distance cue. Animal Behaviour 59, 57-67. doi:10.1006/anbe. 1999.1278

Padgham, M. (2004). Reverberation and frequency attenuation in forests implications for acoustic communication in animals. Journal of the Acoustical Society of America 115, 402-410. doi:10.1121/1.1629304

Parker, K. A., Hauber, M. E., and Brunton, D. H. (2010). Contemporary cultural evolution of a conspecific recognition signal following serial translocations. Evolution 64, 2431-2441.

Podos, J., Sherer, J. K., Peters, S., and Nowicki, S. (1995). Ontogeny of vocal tract movements during song production in Song Sparrows. Animal Behaviour 50, 1287-1296. doi:10.1016/0003-3472(95)80044-1

Richards, D. G. (1981). Estimation of distance of singing conspecifics by the Carolina Wren. Auk 98, 127-133.

Slabbekoorn, H., Ellers, J., and Smith, T. B. (2002). Birdsong and sound transmission: the benefits of reverberations. Condor 104, 564-573. doi:10.1650/0010-5422(2002)104[0564:BASTTB]2.0.CO;2

Slater, P. J. B. (2003). Fifty years of bird song research: a case study in animal behaviour. Animal Behaviour 65, 633-639. doi:10.1006/anbe.2003.2051

Weiss, D. J., and Hauser, M. D. (2002). Perception of harmonics in the combination long call of Cottontop Tamarins, Saguinus oedipus. Animal Behaviour 64, 415-426. doi:10.1006/anbe.2002.3083

Westneat, M. W., Long, J. H., Hoese, W., and Nowicki, S. (1993). Kinematics of birdsong: functional correlation of cranial movements and acoustic features in sparrows. Journal of Experimental Biology 182, 147-171.

Wiley, R. H., and Godard, R. (1996). Ranging of conspecific songs by Kentucky Warblers and its implications for interactions of territorial males. Behaviour 133, 81-102. doi:10.1163/156853996X00044 